\title{
Bioreversible Derivatives of Phenol. 1. The Role of Human Serum Albumin as Related to the Stability and Binding Properties of Carbonate Esters with Fatty Acid-like Structures in Aqueous Solution and Biological Media
}

\author{
Jesper Østergaard* and Claus Larsen ${ }^{\dagger}$ \\ Department of Pharmaceutics and Analytical Chemistry, Faculty of Pharmaceutical Sciences, \\ University of Copenhagen, Universitetsparken 2, DK-2100 Copenhagen O, Denmark; ${ }^{\dagger}$ E-mail: \\ csl@farma.ku.dk
}

* Author to whom correspondence should be addressed. E-mail: joe@farma.ku.dk

Received: 28 September 2007; in revised form: 29 October 2007 / Accepted: 29 October 2007 / Published: 30 October 2007

\begin{abstract}
With the overall objective of assessing the potential of utilizing plasma protein binding interactions in combination with the prodrug approach for improving the pharmacokinetics of drug substances, a series of model carbonate ester prodrugs of phenol, encompassing derivatives with fatty acid-like structures, were characterized in vitro. Stability of the derivatives was studied in aqueous solution, human serum albumin solution, human plasma, and rat liver homogenate at $37^{\circ} \mathrm{C}$. Stability of the derivatives in aqueous solution varied widely, with half-lives ranging from 31 to $1.7 \times 10^{4} \mathrm{~min}$ at $\mathrm{pH} 7.4$ and $37^{\circ} \mathrm{C}$. The carbonate esters were subject to catalysis by plasma esterases except for the $t$-butyl and acetic acid derivatives, which were stabilized in both human plasma and human serum albumin solutions relative to buffer. In most cases, however, hydrolysis was accelerated in the presence of human serum albumin indicating that the derivatives interacted with the protein, a finding which was confirmed using the p-nitrophenyl acetate kinetic assay. Different human serum albumin binding properties of the phenol model prodrugs with fatty acid-like structure and neutral carbonate esters were observed. In the context of utilizing plasma protein binding in combination with the prodrug approach for optimizing drug pharmacokinetics, the esterase-like properties of human serum albumin towards the carbonate esters potentially allowing the protein to act as a catalyst of parent compound regenerations is interesting.
\end{abstract}


Keywords: Bioreversible derivatives, carbonate ester, esterase-like properties, human serum albumin, prodrug, plasma protein binding

\section{Introduction}

Poor pharmacokinetics, together with toxicological issues, are major causes of drug failure during early development. High affinity leads generated in drug discovery seldom possess the physicochemical properties required for transport to the site of action in the body. Although considerable measures are taken to improve the drug-like properties of the hits generated in drug screening programs, e.g. [1-5], simultaneous optimization of pharmacodynamic and pharmacokinetic properties may not always be achievable. Bioreversible derivatization [6-10], i.e. the prodrug approach, allowing transient modification of pharmacokinetic properties may constitute a suitable means for improving drug performance of active agents characterized by possessing favorable receptor profiles but poor transport properties.

Plasma protein binding is a major factor determining the fate of drug substances upon entry into the body [11-14]. Human serum albumin (HSA) interacts with a wide range of endo- and exogenous substances, primarily hydrophobic organic anionic compounds including fatty acids. HSA is quantitatively the most important protein as regards drug-plasma protein binding $[15,16]$. Exploitation of reversible drug-HSA binding in order to obtain improved drug pharmacokinetics has only been utilized in a few cases. The protracted effect of insulin fatty acid analogues is, at least in part, due to reversible binding to albumin [17-19]. Also acylation of glucagon-like peptide-1 derivatives with fatty acids led to protracted action facilitated by albumin binding [20]. Further, sustained release of 5-fluorouracil prodrugs with affinity for HSA was found to be effective against sarcoma in a mouse model [21-23]. In addition to the well-known ligand binding characteristics, HSA has been associated with esterase-like properties [9,24-26] which may be of potential interest in the prodrug setting in relation to regeneration of parent compound.

To assess the potential of utilizing plasma protein binding interactions in combination with the prodrug approach for improving pharmacokinetics, we have studied a series of bioreversible derivatives of the model drug phenol. It is known that several phenolic drugs are susceptible to extensive first-pass metabolism [27]. Therefore, it appeared of interest to investigate whether HSA binding may aid in decreasing the extent of first-pass metabolism of drug candidates containing a phenolic hydroxyl group. Thus, the overall objective of this study was to investigate the potential feasibility of optimizing the pharmacokinetic profile of phenol, i.e. minimizing hepatic first-pass metabolism of phenol, by design of bioreversible derivatives exhibiting a high affinity for HSA. In the current work, we present the in vitro characterization of a series of carbonate esters of phenol encompassing derivatives with fatty acid-like structures (Table 1) with respect to stability in phosphate buffer (pH 7.40), diluted plasma and rat liver homogenate as well as initial studies on the interaction between the carbonate esters and HSA and the implications hereof on carbonate ester reconversion rates. The synthesis of the carbonate ester derivatives is reported in the accompanying work together with detailed studies on the susceptibility of the carbonate esters towards hydrolysis as a function of 
$\mathrm{pH}$ [28]. In the following, bioreversible derivative is used as the preferred term, since phenol is not a drug and consequently the carbonate esters subject to study not prodrug derivatives.

\section{Results and Discussion}

Phenol was selected as a model for drug substances containing a phenolic hydroxyl group because its metabolism has been studied extensively [29-32] and phenol only possess a very weak affinity for HSA [33-35]. Phenol is subject to hepatic metabolism [29-32], the main metabolites being phenyl glucuronide and phenyl sulphate. Furthermore, it has previously been used as a model compound in prodrug related studies aiming at the circumvention of first-pass metabolism [36-39].

Table 1. Chemical structures and numbering of the carbonate ester derivatives subject to investigation. The carboxylic acid ester phenyl acetate was also included in the study.

\begin{tabular}{cll} 
& & \multicolumn{1}{c}{ Name } \\
\hline Compound & \multicolumn{1}{c}{$\mathbf{R}$} & \multicolumn{1}{c}{ Ethyl phenyl carbonate } \\
\hline $\mathbf{1}$ & $-\mathrm{C}_{2} \mathrm{H}_{5}$ & t-Butyl phenyl carbonate \\
$\mathbf{2}$ & $-\mathrm{C}\left(\mathrm{CH}_{3}\right)_{3}$ & Diphenyl carbonate \\
$\mathbf{3}$ & $-\mathrm{C}_{6} \mathrm{H}_{5}$ & 2-(Phenoxycarbonyloxy)-acetic acid \\
$\mathbf{4}$ & $-\mathrm{CH}_{2} \mathrm{COOH}$ & 6-(Phenoxycarbonyloxy)-hexanoic acid \\
$\mathbf{5}$ & $-\left(\mathrm{CH}_{2}\right)_{5} \mathrm{COOH}$ & 8-(Phenoxycarbonyloxy)-octanoic acid \\
$\mathbf{6}$ & $-\left(\mathrm{CH}_{2}\right)_{7} \mathrm{COOH}$ & 12-(Phenoxycarbonyloxy)-dodecanoic acid \\
$\mathbf{7}$ & $-\left(\mathrm{CH}_{2}\right)_{11} \mathrm{COOH}$ & 16-(Phenoxycarbonyloxy)-hexadecanoic acid \\
$\mathbf{8}$ & $-\left(\mathrm{CH}_{2}\right)_{15} \mathrm{COOH}$ & Phenyl acetate \\
$\mathbf{9}$ & & -
\end{tabular}

\section{Hydrolysis in biological media}

Rates of hydrolysis of the carbonate esters and phenyl acetate were determined at $37^{\circ} \mathrm{C}$ in $0.067 \mathrm{M}$ phosphate buffer ( $\mathrm{pH} 7.40$ ) and $80 \%$ (v/v) human plasma. The hydrolysis rates of the carbonate esters in aqueous buffer ( $\mathrm{pH}$ 7.40) were found to follow pseudo-first-order kinetics, however, at widely different rates, with half-lives ranging from $31 \mathrm{~min}$ to $280 \mathrm{~h}$. The results obtained are in agreement with those previously obtained under slightly different conditions [28]. The stability of the carbonate esters in plasma was monitored for up to $8 \mathrm{~h}$ and the degradation reactions were also found to follow pseudo-first-order kinetics (Table 2). Hydrolysis of most of the esters was catalyzed plasma enzymes, however, to varying extents. The neutral esters $\mathbf{1}$ and $\mathbf{3}$ are hydrolysed rapidly with $t_{1 / 2}<2$ min, unlike the sterically hindered $t$-butyl derivative $\mathbf{2}$ (Table 2). The plasma catalyzed hydrolysis for phenyl acetate (9) was too fast to be monitored. In fact, 2 is more stable in $80 \%$ plasma than in buffer at $\mathrm{pH}$ 7.4. This behavior was also observed for the charged acetic acid derivative 4. Plasma protein binding 
of these esters may be the cause of the observed stabilizing effect. Stabilization of bioreversible derivatives in vitro in human plasma relative to aqueous buffer due to plasma protein binding has been found previously for a glutaric acid derivative of phenol [37], various alkyl and aromatic esters of timolol [40,41], a $t$-butyl ester of $L$-dopa [42], a basic carbamate of 4-hydroxyanisole [43], and haloperidol decanoate [44]. With the exception of $t$-butyl phenyl carbonate (2), reconversion to phenol proceeds more slowly for the carbonate esters 4-8 negatively charged at physiological $\mathrm{pH}$ than for the neutral derivatives. However, for the esters with fatty acid-like structure no correlation between the number of methylene groups in the promoiety or lipophilicity [45] and the hydrolysis rates in $80 \%$ human plasma is apparent (Table 2). Generally, esters having a negative charge possess a higher resistance towards plasma catalyzed hydrolysis by being poor substrates for plasma esterases [46-48]. Examples include hemiesters of phenols [37] and metronidazole [49,50], corticosteroids [47] and benzoylglycolic acid [48].

Table 2. Rate data for the decomposition of various carbonate esters and phenyl acetate in $67 \mathrm{mM}$ buffer solution, 4\% HSA solution, 80\% human plasma, and 20\% rat liver homogenate at $37^{\circ} \mathrm{C}^{\text {a) }}$.

\begin{tabular}{|c|c|c|c|c|c|c|}
\hline \multirow[b]{2}{*}{ Compound } & \multicolumn{5}{|c|}{ Half-life \pm SD (min) } & \multirow[b]{2}{*}{$\log P^{d)}$} \\
\hline & $\begin{array}{l}\text { Buffer, } \\
\text { pH 7.40 }\end{array}$ & $\begin{array}{l}4.3 \% \\
\text { HSA } \\
\end{array}$ & $\begin{array}{l}4.3 \% \\
\text { HSA }^{\mathrm{c}} \\
\end{array}$ & $\begin{array}{c}\mathbf{8 0} \% \\
\text { Human plasma } \\
\end{array}$ & $\begin{array}{c}20 \% \text { rat liver } \\
\text { homogenate }\end{array}$ & \\
\hline 1 & $7.9( \pm 1.0) \times 10^{3}$ & $77 \pm 3.2$ & $82 \pm 2.5$ & $1.13 \pm 0.10$ & b) & 2.17 \\
\hline 2 & $31 \pm 0.6$ & $268 \pm 14$ & $248 \pm 24$ & $82 \pm 7.4$ & $0.10 \pm 0.02$ & 3.02 \\
\hline 3 & $4.6( \pm 0.03) \times 10^{2}$ & $14 \pm 2.3$ & $16.9 \pm 1.3$ & $0.18 \pm 0.002$ & b) & 3.21 \\
\hline 4 & $31 \pm 0.2$ & $148 \pm 1.3$ & $147 \pm 5.0$ & $74 \pm 1.0$ & $0.90 \pm 0.16^{f)}$ & 1.72 \\
\hline 5 & $1.7( \pm 0.02) \times 10^{4}$ & $421 \pm 20$ & $422 \pm 4.7$ & $38 \pm 2.8$ & b) & 2.56 \\
\hline 6 & $1.7( \pm 0.15) \times 10^{4}$ & $72 \pm 1.6$ & $70 \pm 1.3$ & $7.5 \pm 1.1$ & b) & 3.39 \\
\hline 7 & $1.4( \pm 0.07) \times 10^{4}$ & $( \pm 0.2) \times 1$ & $0( \pm 2.2) \times 10^{3}$ & $661 \pm 86$ & b) & 4.26 \\
\hline 8 & n.d. ${ }^{\mathrm{g})}$ & $142 \pm 3.9$ & $146 \pm 2.2$ & $40 \pm 2.0$ & $0.12 \pm 0.03$ & 4.67 \\
\hline 9 & $3.0( \pm 0.36) \times 10^{3}$ & $11.9 \pm 0.3$ & $12.6 \pm 0.3$ & b) & b) & $1.49^{\mathrm{e})}$ \\
\hline
\end{tabular}

a) Experiments performed in triplicate.

b) Degraded within $15 \mathrm{~s}$.

c) $1 \times 10^{-4} \mathrm{M}$ physostigmine added to HSA solution.

d) Logarithm to the octanol-water partition coefficient (log P) taken from [45].

e) From [51].

f) Mixed kinetics observed. Half-life calculated from $t_{1 / 2}=\ln 2 /\left(V_{\max } / K_{m}\right) . V_{\max }$ and $K_{m}$ obtained by nonlinear regression analysis using an integrated form of the Michaelis-Menten equation [52].

g) n.d., not determined due to solubility limitations. 


\section{Hydrolysis in HSA solution}

For the negatively charged esters, binding to plasma proteins may also be a contributing factor to the observed high resistance towards plasma esterase catalyzed hydrolysis. This aspect has to our knowledge not been investigated. However, based on the binding specificity of HSA (e.g. references: [15,53-56]) it may be reasonable to suggest that negatively charged derivatives are bound to a higher degree than their neutral counterparts and, thus, rendering the negatively charged esters less accessible for the hydrolytic enzymes. It is well recognized that fatty acids are extensively bound to HSA $[15,53,56]$, the affinity increasing with the chain length of the acid. Targeting to HSA has previously been shown to be successful for various delivery purposes in the case of proteins [17-20] and small organic molecules [57-59]. The bioreversible derivatives 4-8 may show some resemblance to fatty acids having a carboxylic acid group and a lipophilic part including an alkyl chain of varying length. Therefore, their stability in aqueous buffer was investigated in the presence of a physiological concentration of HSA $(662 \mu \mathrm{M})$ to shed light on the effects of protein interactions on the stability of the derivatives. The course of degradation was adequately described by pseudo-first-order kinetics. For the derivative $\mathbf{7}$ being very stable in the HSA solution, first-order kinetics was assumed and for $\mathbf{8}$, the half-live was determined from the rate of phenol formation. Enhanced lability of the derivatives 1, 3, 5, $\mathbf{6}$ and $\mathbf{8}$ in the presence of HSA as compared to $0.067 \mathrm{M}$ phosphate buffer ( $\mathrm{pH} 7.40$ ) was observed, indicating that interaction with HSA takes place. In contrast, derivatives $\mathbf{2}$ and $\mathbf{4}$ were more stable in the HSA containing solution than in buffer suggesting that protein binding is these cases causes increased stability in plasma of the latter derivatives. To this end stabilization towards hydrolysis due to HSA binding has been observed for ester derivatives of salicylic acid and diflunisal [60]. Interestingly, the stability of $\mathbf{7}$ was essentially unaffected by the presence of HSA.

HSA has been found to possess esterase-like properties [24-26,61-63]. Best characterized is probably the catalysis of $p$-nitrophenyl acetate decomposition $[26,63,64]$ which will discussed further below. Compounds studied in a prodrug context include nicotinic acid esters $[65,66]$, acetylsalicylic acid [61], and carbamates of phenol [36,38]. Furthermore, hydrolysis of long chain aryl esters has been found to be catalyzed by HSA [62]. Caution should however be exercised when assigning the catalytic effect to HSA. Commercially available HSA preparations have been found to contain cholinesterase as an impurity, leading to an erroneous assignment of HSA as a catalyst $[67,68]$ as has probably been the case for nicotinic acid esters [65,66]. Therefore, the hydrolysis of the esters in HSA containing solution was also investigated in the presence of $10^{-4} \mathrm{M}$ of physostigmine, a pseudocholinesterase inhibitor. As seen from Table 2, the hydrolysis rates for the carbonate esters in HSA were not affected by the presence of physostigmine, suggesting that cholinesterases are not present in the HSA preparation used or that the carbonate esters are poor substrates for the enzyme. The half-life of phenyl acetate (9) was slightly increased in the presence of the inhibitor $(* \mathrm{P}>0.05)$. Detailed studies are required to assign the hydrolysis of the esters to particular sites on HSA and to entirely exclude hydrolysis occurring due to the presence of other contaminant enzymes. However, to the best of our knowledge this is the first report of the HSA catalysis of carbonate ester degradation. The reconversion of ester prodrug derivatives to parent compound in blood is usually mediated by plasma enzymes or by 
chemical hydrolysis, however, based on the obtained data it may be suggested that specific prodrugs using HSA as a facilitator of parent drug liberation may be designed.

\section{Hydrolysis in rat liver homogenate}

Degradation of the esters was also studied in $20 \%(\mathrm{w} / \mathrm{w})$ rat liver homogenate at $\mathrm{pH} 7.4$ and $37^{\circ} \mathrm{C}$. For most of the derivatives degradation was too fast to be followed (Table 2). Mixed zero- and firstorder kinetics was observed for the acetic acid derivative 4. The rapid hydrolysis of all the esters suggests that none of the promoieties are capable of protecting phenol from hepatic metabolism upon entry into the hepatocyte. In order to protect phenol from hepatic first-pass metabolism the model prodrugs should be able to prevent the derivatives from being taken up by the liver (due to extensive HSA binding) otherwise they will most likely be subject to sequential metabolism [69], i.e. hydrolysis followed by conjugation in the present case.

\section{Affinity of carbonate esters for human serum albumin as studied by a spectrophotometric assay}

The altered stability of the carbonate esters in HSA solution as compared to phosphate buffer solution strongly indicated that the carbonate esters interact with the plasma protein. HSA possesses two major drug binding sites termed site I and site II, respectively, according to the Sudlow nomenclature [15,53,70,71]. It should be appreciated that site I and II are binding areas or regions rather than binding sites $[55,72,73]$ as more than one ligand may be accommodated at a time without considerable interference. Site I ligands are typically heterocyclic anions with the charge placed in the central part of the molecule [71]. However, a large degree of variability in the chemical structure is found among these ligands [55]. Site II ligands are generally aromatic hydrophobic anions with the charge situated in one end of the molecule away from the apolar region [71]. However, site II ligands may also be neutral. The site II binding area is characterized as a hydrophobic pocket with estimated dimensions of $8 \times 16 \AA$ [74]. Irikura et al. estimated a length of 21-25 $\AA$ for the long dimension [75]. Thus, certain size limitations apply for the ligand to be accommodated by HSA. For instance, longchain fatty acids cannot bind to site II in contrast to medium-chain fatty acids with 6 to 10 carbon atoms $[63,74]$. A priori, based on their structure, elongated shape and negative charge positioned at the end of the molecule, the carbonate esters 4-8 with fatty acid-like structure were expected to interact with the HSA binding site II or the long-chain fatty acid binding sites.

The rapid hydrolysis of most of the carbonate esters in the presence of HSA (Table 2) precludes the use of equilibrium methods, and other slow methods, for characterization of the interaction. In order to get some initial insights on the interaction of the bioreversible derivatives of phenol with HSA, a rapid spectrophotometric kinetic assay exploiting the esterase-like properties of HSA was applied $[26,63,76,77]$. The ability of HSA to facilitate the hydrolysis of $p$-nitrophenyl acetate is primarily associated with the Sudlow site II $[64,78]$. The amino acid residues primarily involved are Tyr-411 and Arg-410 [64,78], however, secondary less reactive sites have been recognized $[26,77,79,80]$. The ester $p$-nitrophenyl acetate reacts rapidly with HSA leading to the formation of $p$-nitrophenolate and HSA acetylated (Ac-HSA) at the amino acid residue Tyr-411. The addition of 
ligands (L) may inhibit the acetylation reaction. In the most simple cases, this occurs in a competitive manner through the formation of an unreactive ligand-HSA complex (L·HSA) [26,63,76,77,79-81]. However, it has been found that binding to other sites on albumin, including the long-chain fatty acid binding sites, may also affect the rate of acetylation. The reaction scheme proposed by Means and coworkers $[26,63]$ for the $p$-nitrophenyl acetate - HSA affinity assay is depicted in Scheme 1.

Scheme 1. Reaction scheme for the inhibition of the acetylation of human serum albumin (HSA) by $p$-nitrophenyl acetate ( $p$ NphOAc) by ligand (L) addition [26,63].

$$
\begin{array}{ll} 
& \mathrm{K}_{\mathrm{d}} \\
& +\mathrm{L} \rightleftarrows \mathrm{L} \cdot \mathrm{HSA} \\
\mathrm{HSA} & \\
& + \text { pNphOAc } \rightleftarrows \text { NNphOAc·HSA } \rightarrow \text { Ac-HSA }+p \text {-nitrophenolate }
\end{array}
$$

In accordance with previous investigations, the degradation of $p$-nitrophenyl acetate was found to follow pseudo-first-order kinetics when HSA was present in excess of $p$-nitrophenyl acetate. This was the case both in the absence and presence of added ligands. Using a HSA concentration of $7 \times 10^{-5} \mathrm{M}$, a half-life of $\sim 10 \mathrm{~s}$ for the degradation of $p$-nitrophenyl acetate was observed in the absence of ligand in the $0.067 \mathrm{M}$ phosphate buffer at $\mathrm{pH} 7.40$ and $37^{\circ} \mathrm{C}$. The $\mathrm{t}_{1 / 2}$ of $p$-nitrophenyl acetate in the phosphate buffer at pH 7.40 without HSA was 355 min. At the selected conditions, the reaction was of first-order with respect to $p$-nitrophenyl acetate and proportional to the concentration of free (unoccupied) HSA when taking into account the formation of $p$-nitrophenolate due to reaction with secondary HSA sites and chemical hydrolysis [26]:

$$
\frac{[\mathrm{HSA}]}{[\mathrm{HSA}]_{\text {total }}}=\frac{\mathrm{k}-\mathrm{k}_{\mathrm{res}}}{\mathrm{k}_{0}-\mathrm{k}_{\mathrm{res}}}
$$

where [HSA] and [HSA $]_{\text {total }}$ are the concentration of primary free binding sites on HSA in the presence and absence of added ligand, respectively. $\mathrm{k}$ and $\mathrm{k}_{0}$ are the pseudo-first-order rate constants in the presence and absence of added ligand, respectively, and $k_{\text {res }}$ is the apparent rate constant due to other reactions of $p$-nitrophenyl acetate with HSA leading to the formation of $p$-nitrophenolate. The magnitude of $\mathrm{k}_{\text {res }}$ was determined from experiments conducted with ibuprofen added in large excess of HSA (10-20 equivalents) and the rate was found to correspond to $6 \%$ of the uninhibited reaction. All of the carbonate esters investigated inhibited the reaction between $p$-nitrophenyl acetate and HSA. The neutral carbonate esters (ethyl phenyl, $t$-butyl phenyl and diphenyl, 1-3), did so, however, to a much lesser extent than the carbonate esters with fatty-acid like structure, as can be seen from Figure 1. According to convention the ratio of $\mathrm{k} / \mathrm{k}_{0}$ was plotted as a function of the ligand/HSA ratio rather than the right hand side of Equation 1. The ability of the parent compound phenol and phenyl acetate (9) to inhibit the actylation reaction was also investigated and results qualitatively similar to that of the carbonate esters 1-3 were obtained (data not shown). Figure 1B shows that 2-(phenoxycarbonyloxy)acetic acid (4) inhibited the reaction more strongly than the longer hexanoic acid and octanoic acid 
derivatives. Also, it is apparent that the inhibition profiles of the derivatives are different from those of the site II ligands ibuprofen and octanoic acid, the differences being most prominent for $\mathbf{6 , 7}$ and $\mathbf{8}$. For comparison, the inhibitory effect of the site II ligands ibuprofen and octanoic acid was investigated as well. In agreement with previous reports, the affinity for HSA of ibuprofen was higher than that of octanoic acid [79]. Ibuprofen and octanoic acid proved to be more efficient inhibitors of the acetylation reaction than any of the carbonate esters (Figure 1). Plotting of the obtained rate data according to Koh and Means [63] indicated that only 2-(phenoxycarbonyloxy)-acetic acid (4), in addition to octanoic acid and ibuprofen, had Sudlow site II as the primary and/or only binding site. Apparent dissociation constants were estimated using linear regression analysis, the values being $2.6 \times 10^{-5} \mathrm{M}, 5.4 \times 10^{-6} \mathrm{M}$ and $5.7 \times 10^{-6} \mathrm{M}$ for 2-(phenoxycarbonyloxy)-acetic acid (4), octanoic acid and ibuprofen, respectively. It may tentatively be suggested that the longer carbonate ester derivatives (5-8) may have other binding sites than site II, possible the long-chain fatty acid binding sites, as their primary area of interaction. The spectrophotometric affinity assay did not allow quantitative assessment of the binding parameters of the carbonate esters, except for derivative 4. However, the assay revealed that the mode and degree of interaction with HSA is different for derivatives with fatty acid-like structure than the neutral carbonate esters. From the rate data and the stability studies in $80 \%$ plasma and HSA containing solution it may also be stipulated that the charged derivatives interact strongly with HSA.

Figure 1. Inhibition of the reaction of $p$-nitrophenyl acetate with human serum albumin (HSA) by the addition of ligand in $0.067 \mathrm{M}$ sodium phosphate buffer $\mathrm{pH} 7.40$ and $37^{\circ} \mathrm{C}$. The degree of inhibition, expressed as the ratio of the observed first-order rate constants in the presence of ligand, $\mathrm{k}$, and absence of ligand, $\mathrm{k}_{0}$, as a function of the ligand to HSA concentration ratio. (A). Ligands: $1(\bullet), 2(\bigcirc), 3(\Delta)$, ibuprofen $(\triangle)$, and octanoic acid $(\boldsymbol{\nabla})$. (B) Ligands: $4(\bigcirc), 5(\bigcirc), 6(\times)$, ibuprofen $(\triangle)$, and octanoic acid $(\boldsymbol{\nabla})$. (C) Ligands: 7 $(\bigcirc), 8(\bigcirc)$, ibuprofen $(\triangle)$, and octanoic acid $(\boldsymbol{\nabla})$.

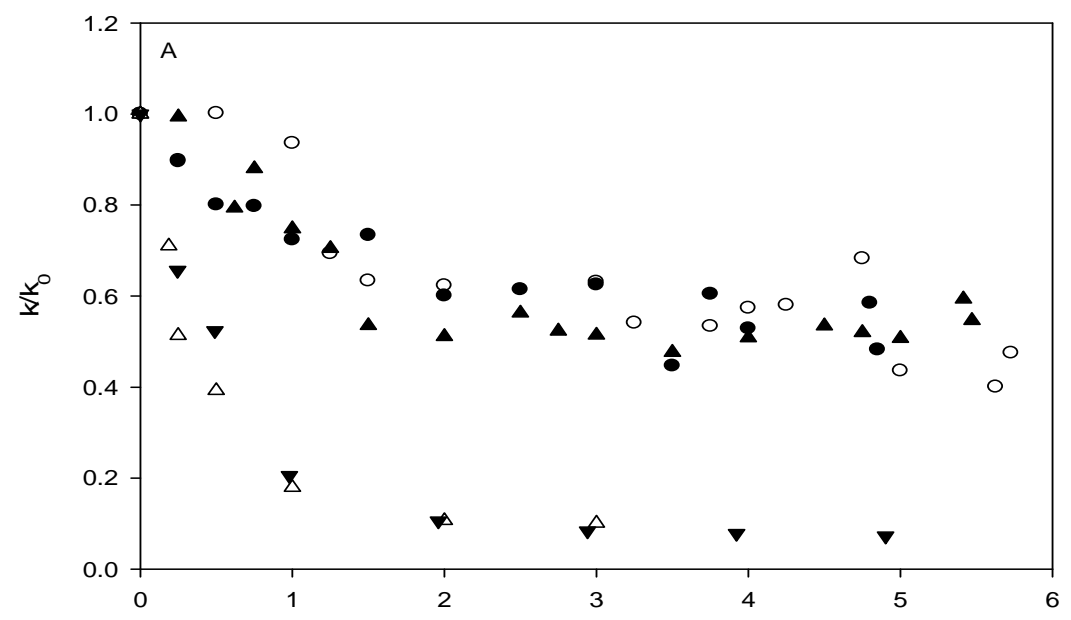


Figure 1. Cont.
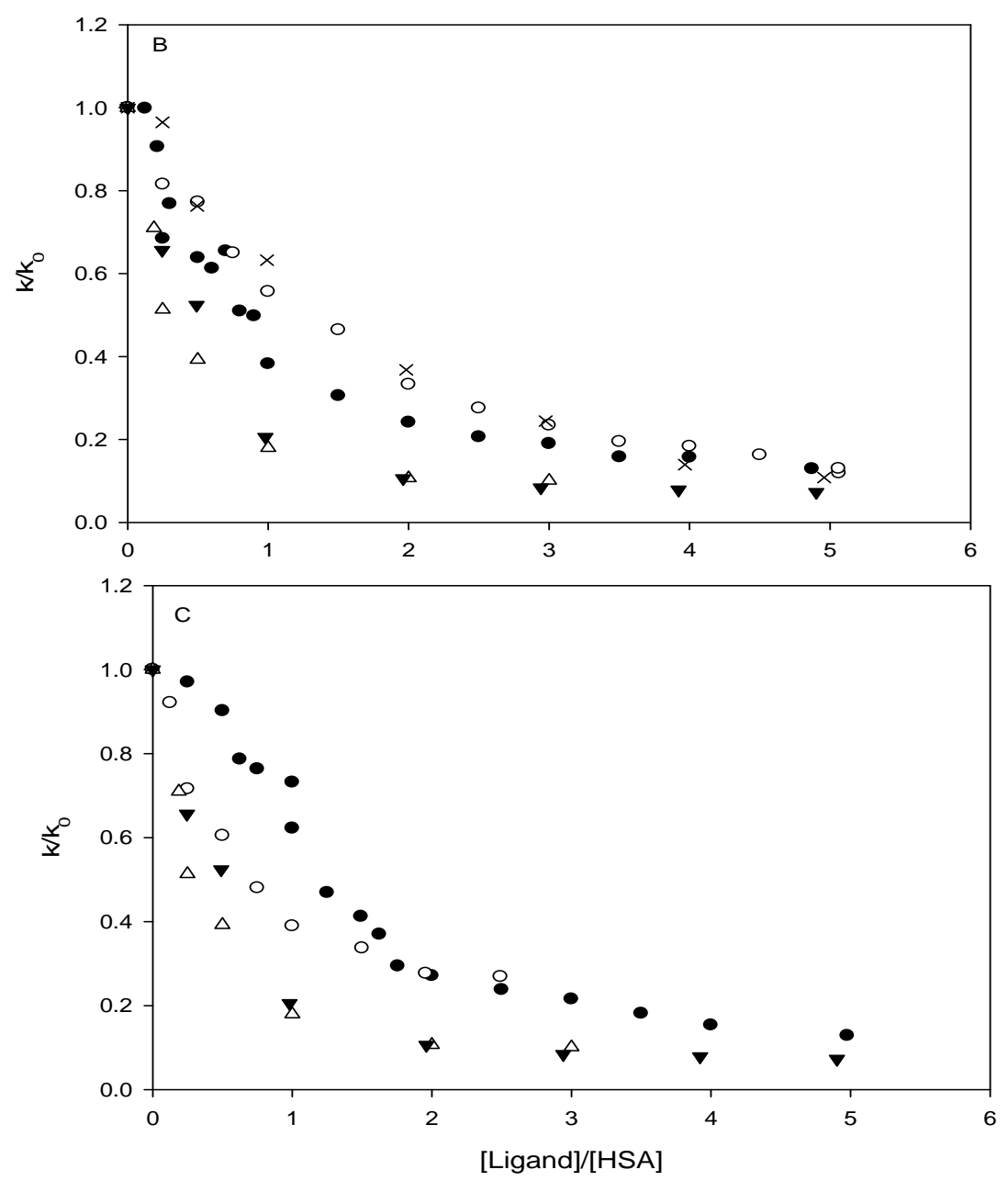

\section{Conclusions}

The in vitro fate of eight carbonate esters of phenol, some with fatty acid-like structure, upon incubation in diluted human plasma and a phosphate buffer solution with a near physiological human serum albumin (HSA) concentration, was studied. The degradation of the carbonate esters was catalyzed by plasma as compared to their stability in buffer at $\mathrm{pH} 7.4$, except for the relatively unstable t-butyl and acetic acid derivatives 2 and 4, which were stabilized by the presence of plasma proteins. The presence of HSA in the incubation medium was found to significantly influence the degradation rates of the model prodrug carbonate esters. Again, for the $t$-butyl and acetic acid derivatives a stabilizing effect was observed, however, for five of the model prodrugs a catalytic effect of HSA was observed for the first time. These results, indicating that the carbonate esters interacted with HSA were confirmed by the $p$-nitrophenyl acetate kinetic affinity assay. The inhibition patterns obtained from the kinetic assay suggest that bioreversible derivatives with fatty acid-like structure, negatively charged at physiological $\mathrm{pH}$, interacted more strongly with HSA than the neutral counterparts although quantitive estimates of affinity were not obtained.

As relates to the potential of exploiting plasma protein binding together with the prodrug approach for improving drug pharmacokinetics, the possibility of using HSA as a catalyst of parent compound 
regeneration is highly interesting and warrants further investigation. The model prodrug derivatives of phenol subject to the conducted in vitro characterization appear suitable for further investigations of this concept. Especially derivatives 4, $\mathbf{7}$ and $\mathbf{8}$ may be suited for further testing e.g. in hepatocyte suspensions or single pass rat liver perfusion studies due to their in vitro affinity and stability properties. Protein binding has been suggested to be a potentially limiting step in liver uptake [82]. Optimal bioreversible derivatization for preventing phenol from being first-pass metabolized in the liver most likely requires extensive HSA binding in order to minimize prodrug uptake into hepatocytes. Current studies in our lab are directed at developing methods suitable for quantitative evaluation of the binding between bioreversible derivatives and HSA.

\section{Experimental}

\section{Chemicals}

Eserine hemisulfate salt (physostigmine), ethyl phenyl carbonate, and human serum albumin ( $\geq$ 96\% albumin, essentially fatty acid free, A-1887, lot 90K7604), and ibuprofen were obtained from Sigma Chemical Co. (St. Louis, MO, USA). Phenyl acetate was obtained from Acros Organics (Geel, Belgium). Diphenyl carbonate, phenol, $p$-nitrophenyl acetate, octanoic acid, and t-butyl phenyl carbonate were obtained from Aldrich-Chemie (Steinheim, Germany). 2-(Phenoxycarbonyloxy)-acetic acid, 6-(phenoxycarbonyloxy)-hexanoic acid, 8-(phenoxycarbonyloxy)-octanoic acid, 12-(phenoxycarbonyloxy)-dodecanoic acid, and 16-(phenoxycarbonyloxy)-hexadecanoic acid were synthesized and characterized as described elsewhere [28]. All other chemicals and solvents were of analytical grade or better. Purified water from a Milli-Q deionization unit (Millipore, Bedford, MA, USA) was used throughout.

\section{Apparatus}

An Aquarius CE7200 UV-spectrophotometer (Cecil Instruments, Cambridge, England) equipped with a thermostatted cell compartment, using $10 \mathrm{~mm}$ quartz cuvettes, was used for measurement of the p-nitrophenyl acetate decomposition. Data was collected and transferred to Microsoft Excel using HyperAccess Ver. 8.4 software (Hilgraeve, Monroe, MI, USA). HPLC was performed using a MerckHitachi L-6200 pump, a L-4000 UV-detector, and a D-2000 Chromato-Integrator (Merck-Hitachi, Tokyo, Japan) equipped with a Rheodyne 7125 injection valve with a $20 \mu \mathrm{L}$ loop. A ChromSpher C18 $(150 \times 4.6 \mathrm{~mm} ; 5 \mu \mathrm{m}$ particles) column (Chrompack Varian, The Netherlands) was used and the mobile phases consisted of acetonitrile $-0.1 \% \mathrm{v} / \mathrm{v}$ phosphoric acid in suitable proportions (10 to $70 \%$ $\mathrm{v} / \mathrm{v}$ of acetonitrile). The flow rate was set at $1 \mathrm{~mL} / \mathrm{min}$ and the effluent was monitored at $200 \mathrm{~nm}$.

\section{Kinetic measurements}

Stability of the phenol derivatives was studied in $0.067 \mathrm{M}$ sodium phosphate buffer solution at 37 $\pm 0.2^{\circ} \mathrm{C}$. The buffer solutions were kept in a water bath at constant temperature, and at appropriate time 
intervals samples were withdrawn and chromatographed immediately. The experiments were initiated by addition of a stock solution in acetonitrile to the buffer solution providing an organic solvent concentration of $1 \%$ or less and an initial ester concentration of approximately $1 \times 10^{-4} \mathrm{M}$. The pseudofirst-order rate constants were determined by linear plots of the logarithm of intact derivative versus time or by using the initial rate method [83]. Carbonate ester degradation was also studied in $4.3 \%$ (w/v) HSA in $0.067 \mathrm{M}$ phosphate buffer ( $\mathrm{pH} 7.40$ ), human plasma diluted to $80 \%$ (v/v) with $0.067 \mathrm{M}$ phosphate buffer ( $\mathrm{pH} 7.40)$, and $20 \%(\mathrm{w} / \mathrm{w})$ rat liver homogenate at $37^{\circ} \mathrm{C}$. The rat liver homogenate was prepared by addition of a calculated amount of $0.067 \mathrm{M}$ phosphate buffer $(\mathrm{pH} 7.40$ ) to the livers followed by homogenization at $4^{\circ} \mathrm{C}$. Samples were withdrawn at appropriate intervals and deproteinized by addition of methanol, acetonitrile or $5 \%(\mathrm{v} / \mathrm{v})$ perchloric acid. Upon centrifugation the supernatant was analyzed by HPLC.

p-Nitrophenyl acetate - human serum albumin affinity assay

The formation of $p$-nitrophenolate due to the reaction between $p$-nitrophenyl acetate and HSA in the presence or absence of ligand (carbonate esters, phenyl acetate, ibuprofen, or octanoic acid) added was monitored as a function of time at $401 \mathrm{~nm}$ by UV-Vis spectrophotometry. The cause of reaction was followed in thermostatted quarts cuvettes at $37 \pm 0.2^{\circ} \mathrm{C}$ filled with $0.067 \mathrm{M}$ sodium phosphate buffer ( $\mathrm{pH} 7.40$ ) containing $1 \% \mathrm{v} / \mathrm{v}$ acetonitrile. The reaction solution contained $7 \times 10^{-5} \mathrm{M}$ HSA and the investigated ligand in the concentration range $0-3.5 \times 10^{-4} \mathrm{M}$ which was preheated for $10-15$ min prior to the start of experiments. Reaction was initiated by addition of $10 \mu \mathrm{L}$ of $p$-nitrophenyl acetate providing a final concentration of $5 \times 10^{-6} \mathrm{M}$ followed by rapid mixing. The degradation of $p$ nitrophenyl acetate followed pseudo-first-order kinetics and the rate constants were obtained from the slopes of linear plots of $\ln \left(A_{\infty}-A_{t}\right)$ versus time $t$, where $A_{\infty}$ and $A_{t}$ are the absorbance measured at time infinity and $t$, respectively [83].

\section{References}

1. Lipinski, C. A.; Lombardo, F.; Dominy, B. W.; Feeney, P. J. Experimental and computational approaches to estimate solubility and permeability in drug discovery and development settings. Adv. Drug Del. Rev. 1997, 23, 3-25.

2. Avdeef, A. Physicochemical profiling (Solubility, permeability and charge state). Curr. Topics Med. Chem. 2001, 1, 277-351.

3. Muegge, I. Selection criteria for drug-like compounds. Med. Res. Rev. 2003, 23, 302-321.

4. van de Waterbeemd, H.; Smith, D. A.; Beumont, K.; Walker, D. K. Property-based design: optimization of drug absorption and pharmacokinetics. J. Med. Chem. 2001, 44, 1313-1333.

5. Walters, W. P.; Murcko, A.; Murcko, M. A. Recognizing molecules with drug-like properties. Curr. Opin. Chem. Biol. 1999, 3, 384-387.

6. Bundgaard, H. Design of prodrugs: Bioreversible derivatives for various functional groups and chemical entities. In Design of prodrugs; Bundgaard, H., Ed.; Elsevier: Amsterdam, 1985; pp. 192. 
7. Larsen, C. S.; Østergaard, J. Design and application of prodrugs. In Textbook of drug design and discovery, 3 ed.; Krogsgaard-Larsen, P., Liljefors, T., Madsen, U., Eds.; Taylor \& Francis: London, 2002; pp. 410-458.

8. Testa, B.; Mayer, J. M. Concepts in prodrug design to overcome pharmacokinetic problems. In Pharmacokinetic optimization in drug research, Testa, B., van de Waterbeemd, H., Folkers, G., Guy, R., Eds.; Verlag Helvetica Chimica Acta/Wiley-VCH: Zürich, 2001; pp. 85-95.

9. Testa, B.; Mayer, J. M. Hydrolysis in drug and prodrug metabolism. Chemistry, biochemistry, and enzymology; Verlag Helvetica Chimica Acta: Zürich, 2003.

10. Stella, V. J.; Borchardt, R. T.; Hageman, M. J.; Oliyai, R.; Maag, H.; Tilley, J. W. Eds. Prodrugs: challenges and rewards. Part 1; Springer-AAPS Press: New York, 2007.

11. Jusko, W. J.; Gretch, M. Plasma and tissue protein binding of drugs in pharmacokinetics. Drug Metab. Rev. 1976, 5, 43-140.

12. Kwong, T. C. Free drug measurements: methodology and clinical significance. Clin. Chim. Acta 1985, 151, 193-216.

13. Vallner, J. J. Binding of drugs by albumin and plasma protein. J. Pharm. Sci. 1977, 66, 447-465.

14. Meyer, M. C.; Guttmann, D. E. The binding of drugs by plasma proteins. J. Pharm. Sci. 1968, 57, 895-918.

15. Peters, T. Jr. All about albumin. Biochemistry, genetics, and medical applications; Academic Press: San Diego, 1996.

16. Kragh-Hansen, U.; Chuang, V. T. G.; Otagiri, M. Practical aspects of the ligand-binding and enzymatic properties of human serum albumin. Biol. Pharm. Bull. 2002, 25, 695-704.

17. Kurtzhals, P.; Havelund, S.; Jonassen, I.; Kiehr, B.; Larsen, U. D.; Ribel, U.; Markussen, J. Albumin binding of insulins acylated with fatty acids: characterization of the ligand-protein interaction and correlation between binding affinity and timing of the insulin effect in vivo. Biochem. J. 1995, 312, 725-731.

18. Kurtzhals, P.; Havelund, S.; Jonassen, I.; Markussen, J. Effect of fatty acids and selected drugs on the albumin binding of a long-acting, acylated insulin analogue. J. Pharm. Sci. 1997, 86, 13651368.

19. Markussen, J.; Havelund, S.; Kurtzhals, P.; Andersen, A. S.; Halstrøm, J.; Hasselager, E.; Larsen, U. D.; Ribel, U.; Schäffer, L.; Vad, K.; Jonassen, I. Soluble, fatty acid acylated insulins bind to albumin and show protracted action in pigs. Diabetologia 1996, 39, 281-288.

20. Knudsen, L. B.; Nielsen, P. F.; Huusfeldt, P. O.; Johansen, N. L.; Madsen, K.; Pedersen, F. Z.; Thøgersen, H.; Wilken, M.; Agersø, H. Potent derivatives of glucagon-like peptide-1 with pharmacokinetic properties suitable for once daily administration. J. Med. Chem. 2000, 43, 16641669.

21. Oku, N.; Yamashita, S.; Sakuragi, n.; Doi, K.; Okada, S.; Shimidzu, K.; Sumi, M.; Nadai, T.; Kusumoto, S.; Suda, Y. Therapeutic efficacy of 5-fluorouracil prodrugs using endogenous serum proteins as drug carriers: A new strategy in drug delivery system. Biol. Pharm. Bull. 1995, 18, 181-184. 
22. Suda, Y.; Shimidzu, K.; Sumi, M.; Oku, N.; Kusumoto, S.; Nadai, T.; Yamashita, S. The synthesis and in vitro and in vivo stability of 5-fluorouracil prodrugs which possess serum albumin binding potency. Biol. Pharm. Bull. 1993, 16, 876-878.

23. Yamashita, S.; Suda, Y.; Masada, M.; Nadai, T.; Sumi, M. 5-Fluorouracil derivatives with serum protein binding potencies. Chem. Pharm. Bull. 1989, 37, 2861-2863.

24. Tove, S. B. The esterolytic activity of serum albumin. Biochim. Biophys. Acta 1962, 57, 230-235.

25. Taylor, R. P. Enzyme-like activities associated with albumin. In Albumin structure, function and uses, 1 ed.; Rosenoer, V. M., Oratz, M., Rotschild, M. A., Eds.; Pergamon Press: Oxford, 1977; pp. 183-201.

26. Means, G. E.; Bender, M. L. Acetylation of human serum albumin by p-nitrophenyl acetate. Biochemistry 1975, 14, 4989-4994.

27. Pond, S. M.; Tozer, T. N. First-pass elimination. Basic concepts and clinical consequenses. Clin. Pharmacokinet. 1984, 9, 1-25.

28. Østergaard, J.; Larsen, C. Bioreversible derivatives of phenol. II. Reactivity of carbonate esters with fatty-acid like structure towards hydrolysis in aqueous solutions. Molecules 2007, 12, 23962412.

29. Ballinger, L. N.; Cross, S. E.; Roberts, M. S. Availability and mean transit times of phenol and its metabolites in the isolated perfused rat liver: Normal and retrograde studies using tracer concentrations of phenol. J. Pharm. Pharmacol. 1995, 47, 949-956.

30. Scott, D. O.; Lunte, C. E. In vivo microdialysis sampling in the bile, blood, and liver of rats to study the disposition of phenol. Pharm. Res. 1993, 10, 335-342.

31. Cassidy, M. K.; Houston, J. B. In vivo assessment of extrahepatic conjugative metabolism in first pass effects using the model compound phenol. J. Pharm. Pharmacol. 1980, 32, 57-59.

32. Cassidy, M. K.; Houston, J. B. In vivo capacity of hepatic and extrahepatic enzymes to conjugate phenol. Drug Metab. Disp. 1984, 12, 619-624.

33. Østergaard, J.; Schou, C.; Larsen, C.; Heegaard, N. H. H. Evaluation of capillary electrophoresis frontal analysis for the study of low molecular weight drug-human serum albumin interactions. Electrophoresis 2002, 23, 2842-2853.

34. Judis, J. Binding of selected phenol derivatives to human serum proteins. J. Pharm. Sci. 1982, 71, 1145-1147.

35. Ogata, N.; Shibata, T. Binding of alkyl- and alkoxy-substituted simple phenolic compounds to human serum proteins. Res. Commun. Chem. Pathol. Pharmacol. 2000, 107, 167-173.

36. Hansen, J.; Mørk, N.; Bundgaard, H. Phenyl carbamates of amino acids as prodrug forms for protecting phenols against first-pass metabolism. Int. J. Pharm. 1992, 81, 253-261.

37. Fredholt, K.; Mørk, N.; Begtrup, M. Hemiesters of aliphatic dicarboxylic acids as cyclizationactivated prodrug forms for protecting phenols against first-pass metabolism. Int. J. Pharm. 1995, 123, 209-216.

38. Thomsen, K. F.; Bundgaard, H. Cyclization-activated phenyl carbamate prodrug forms for protecting phenols against first-pass metabolism. Int. J. Pharm. 1993, 91, 39-49. 
39. Thomsen, K. F.; Strøm, F.; Sforzini, B. V.; Begtrup, M.; Mørk, N. Evaluation of phenyl carbamates of ethyl diamines as cyclization-activated prodrug forms for protecting phenols against first-pass metabolism. Int. J. Pharm. 1994, 112, 143-152.

40. Bundgaard, H.; Buur, A.; Chang, S.-C.; Lee, V. H. L. Timolol prodrugs: synthesis, stability and lipophilicity of various alkyl, cycloalkyl and aromatic esters of timolol. Int. J. Pharm. 1988, 46, 77-88.

41. Bundgaard, H.; Buur, A.; Chang, S.-C.; Lee, V. H. L. Prodrugs of timolol for improved ocular delivery: synthesis, hydrolysis kinetics and lipophilicity of various timolol esters. Int. J. Pharm. 1986, 33, 15-26.

42. Brunner-Guenat, M.; Carrupt, P.-A.; Lisa, G.; Testa, B.; Rose, S.; Thomas, K.; Jenner, P.; Ventura, P. Esters of L-dopa: Structure-hydrolysis relationships and ability to induce circling behaviour in an experimental model of hemiparkinsonism. J. Pharm. Pharmacol. 1995, 47, 861869.

43. Saari, W. S.; Schwering, J. E.; Lyle, P. A.; Smith, S. J.; Engelhardt, E. L. Cyclization-activated prodrugs. Basic carbamates of 4-hydroxyanisole. J. Med. Chem. 1990, 33, 97-101.

44. Nambu, K.; Miyazaki, H.; Nakanishi, Y.; Oh-E, Y.; Matsunaga, Y.; Hashimoto, M. Enzymatic hydrolysis of haloperidol decanoate and its inhibition by proteins. Biochem. Pharmacol. 1987, 36, 1715-1722.

45. Østergaard, J.; Hansen, S. H.; Larsen, C.; Schou, C.; Heegaard, N. H. H. Determination of octanol-water partition coefficients for carbonate esters and other small organic molecules by microemulsion electrokinetic chromatography. Electrophoresis 2003, 24, 1038-1046.

46. Krisch, K. Carboxylic ester hydrolases. In The enzymes, 3 ed.; Boyer, P. D., Ed.; Academic Press: New York, 1971; pp. 43-69.

47. Anderson, B. D.; Conradi, R. A.; Spilman, C. H.; Forbes, A. D. Strategies in the design of solution-stable, water-soluble prodrugs III: Influence of the pro-moiety on the bioconversion of 21-esters of corticosteroids. J. Pharm. Sci. 1985, 74, 382-387.

48. Nielsen, N. M.; Bundgaard, H. Prodrug as drug delivery systems. 68. Chemical and plasmacatalyzed hydrolysis of various esters of benzoic acid: a reference system for designing prodrug esters of carboxylic acid agents. Int. J. Pharm. 1987, 39, 75-85.

49. Larsen, C.; Kurtzhals, P.; Johansen, M. Kinetics of regeneration of metronidazole from hemiesters of maleic acid, succinic acid and glutaric acid in aqueous buffer, human plasma and pig liver homogenate. Int. J. Pharm. 1988, 41, 121-129.

50. Johansen, M.; Larsen, C. Stability and kinetics of hydrolysis of metronidazole monosuccinate in aqueous solution and in plasma. Int. J. Pharm. 1984, 21, 201-209.

51. Hansch, C.; Leo, A.; Hoekman, D. Exploring QSAR. Hydrophobic, electronic, and steric constants; 1 ed.; ACS: Washington, 1995; Vol. 2.

52. Nielsen, N. M.; Bundgaard, H. Glycolamide esters as biolabile prodrugs of carboxylic acid agents: Synthesis, stability, bioconversion, and physicochemical properties. J. Pharm. Sci. 1988, 77, 285298.

53. Carter, D. C.; Ho, J. X. Structure of serum albumin. Adv. Protein Chem. 1994, 45, 153-203. 
54. Kragh-Hansen, U. Molecular aspects of ligand binding to serum albumin. Pharmacol. Rev. 1981, 33, 17-53.

55. Kragh-Hansen, U. Structure and ligand binding properties of human serum albumin. Dan. Med. Bull. 1990, 37, 57-84.

56. Vorum, H. Reversible ligand binding to human serum albumin. Theoretical and clinical aspects. Dan. Med. Bull. 1999, 46, 379-399.

57. Charbon, V.; Latour, I.; Lambert, D. M.; Buc-Calderon, P.; Neuvens, L.; De Keyser, J.-L.; Gallez, B. Targeting of drug to the hepatocytes by fatty Acids. Influence of the carrier (albumin or galactosylated albumin) on the fate of the fatty acids and their analogs. Pharm. Res. 1996, 13, 2731.

58. Gallez, B.; Debuyst, R.; Demeure, R.; Dejehet, F.; Grandin, C.; Van Beers, B.; Taper, H.; Pringot, J.; Dumont, P. Evaluation of a Nitroxyl Fatty Acid as Liver Contrast Agent for Magnetic Resonance Imaging. Magn. Reson. Med. 1993, 30, 592-599.

59. Lambert, D. M. Rationale and applications of lipids as prodrug carriers. Eur. J. Pharm. Sci. 2000, 11 (Suppl. 2), S15-S27.

60. Hung, D. Y.; Mellick, G. D.; Prankerd, R. J.; Roberts, M. S. Synthesis, identification, characterization, stability, solubility, and protein binding of ester derivatives of salicylic acid and diflunisal. Int. J. Pharm. 1997, 153, 25-39.

61. Aarons, L.; Clifton, P.; Fleming, G.; Rowland, M. Aspirin binding and the effect of albumin on spontaneous and enzyme-catalysed hydrolysis. J. Pharm. Pharmacol. 1980, 32, 537-543.

62. Wolfbeis, O. S.; Gürakar, A. The effect of fatty acid chain length on the rate of arylester hydrolysis by various albumins. Clin. Chim. Acta 1987, 164, 329-337.

63. Koh, S.-W. M.; Means, G. E. Characterization of a small apolar anion binding site of human Serum albumin. Arch. Biochem. Biophys. 1979, 192, 73-79.

64. Sakurai, Y.; Ma, S.-F.; Watanabe, H.; Yamaotsu, N.; Hirono, S.; Kurono, Y.; Kragh-Hansen, U.; Otagiri, M. Esterase-like activity of serum albumin: characterization of its structural chemistry using p-nitrophenyl esters as substrates. Pharm. Res. 2004, 21, 285-292.

65. Salvi, A.; Carrupt, P.-A.; Mayer, J. M.; Testa, B. Esterase-like activity of human serum albumin toward prodrug esters of nicotinic acid. Drug Metabol. Dispos. 1997, 25, 395-398.

66. Steiner, A.; Mayer, J. M.; Testa, B. Nicotinate esters: Their binding to and hydrolysis by human serum albumin. J. Pharm. Pharmacol. 1992, 44, 745-749.

67. Whelpton, R.; Hurst, P. R. The binding of physostigmine to human serum albumin. J. Pharm. Pharmacol. 1990, 42, 804-805.

68. Chapuis, N.; Brühlmann, C.; Reist, M.; Carrupt, P.-A.; Mayer, J. M.; Testa, B. The esterase-like activity of serum albumin may be due to cholinesterase contamination. Pharm. Res. 2001, 18, 1435-1439.

69. Stella, V. J.; Charman, W. N.; Naringrekar, V. H. Prodrugs. Do they have advantages in clinical practice? Drugs 1985, 29, 455-473.

70. Sudlow, G.; Birkett, D. J.; Wade, D. N. The characterization of two specific drug binding sites on human serum albumin. Mol. Pharmacol. 1975, 11, 824-832. 
71. Sudlow, G.; Birkett, D. J.; Wade, D. N. Further characterization of specific drug binding sites on human serum albumin. Mol. Pharmacol. 1976, 12, 1052-1061.

72. Fehske, K. J.; Müller, W. E.; Wollert, U. The location of drug binding sites in human serum albmin. Biochem. Pharmacol. 1981, 30, 687-692.

73. Kragh-Hansen, U. Evidence for a large and flexible region of human serum albumin possessing high affinity binding sites for salicylate, warfarin, and other ligands. Mol. Pharmacol. 1988, 34, 160-171.

74. Wanwimolruk, S.; Birkett, D. J.; Brooks, P. M. Structural requirements for drug binding to site II on human serum albumin. Mol. Pharmacol. 1983, 24, 458-463.

75. Irikura, M.; Takadate, A.; Goya, S.; Otagiri, M. 7-Alkylaminocoumarin-4-acetic acids as fluorescent probe for studies of drug-binding sites on human serum albumin. Chem. Pharm. Bull. 1991, 39, 724-728.

76. Sollenne, N. P.; Means, G. E. Characterization of a specific drug binding site of human serum albumin. Mol. Pharmacol. 1979, 15, 754-757.

77. Kurono, Y.; Ohta, N.; Yotsuynagi, T.; Ikeda, K. Effect of drug binding on the esterase-like activity of human serum albumin. III. Evaluation of reactivities of the two active sites by using clofibric acid as an inhibitor. Chem. Pharm. Bull. 1981, 29, 2345-2350.

78. Watanabe, H.; Tanase, S.; Nakajou, K.; Maruyama, T.; Kragh-Hansen, U.; Otagiri, M. Role of Arg-410 and Tyr-411 in human serum albumin for ligand binding and esterase-like activity. Biochem. J. 2000, 349, 813-819.

79. Kurono, Y.; Ozeki, Y.; Yamada, H.; Takeuchi, T.; Ikeda, K. Effects of drug binding on the esterase-like activity of human serum albumin. VII. Subdivision of R-type drugs inhibiting the activity towards p-nitrophenyl acetate. Chem. Pharm. Bull. 1987, 35, 734-739.

80. Ozeki, Y.; Kurono, Y.; Yotsuynagi, T.; Ikeda, K. Effects of drug binding on the esterase activity of human serum albumin: Inhibition modes and binding sites of anionic drugs. Chem. Pharm. Bull. 1980, 28, 535-540.

81. Kurono, Y.; Ikeda, K. Effect of drug binding on the esterase-like activity of human serum albumin. IV. Application of an analog computer to determination of the multiple dissociation constants. Chem. Pharm. Bull. 1981, 29, 2993-3002.

82. Weisiger, R. A. Dissociation from albumin: A potentially rate-limiting step in the clearance of substances by the liver. Proc. Natl. Acad. Sci. USA 1985, 82, 1563-1567.

83. Connors, K. A. Chemical kinetics. The study of reaction rates in solution; VCH Publishers: New York, 1990.

(c) 2007 by MDPI (http://www.mdpi.org). Reproduction is permitted for noncommercial purposes. 